\title{
Sustainability without geology? A shortsighted approach
}

Andrea Fildani ${ }^{1}$ and Angela M. Hessler ${ }^{1}$

${ }^{1}$ The Deep Time Institute, 13809 Research Boulevard, Suite 500, 94952, Austin, Texas 78750, USA

Andrea Fildani; afildani@deeptimeinstitute.org

Angela M. Hessler: ahessler@deeptimeinstitute.org

This is a Post-Print (peer-reviewed and corrected) of Fildani \& Hessler, 2021, "Sustainability without Geology? A shortsighted approach", published on The Sedimentary Record (TSR), 19, 2 , 1-4. doi: 10.2110/sedred.2021.2.1 


\section{Sustainability without geology? A shortsighted approach}

3 Andrea Fildani ${ }^{1}$ and Angela M. Hessler ${ }^{1}$

$4{ }^{I}$ The Deep Time Institute, 13809 Research Boulevard, Suite 500, 94952, Austin, Texas

5 78750, USA

"There are no beautiful surfaces without a terrible depth." F.W. Nietzsche

Over the last few decades, the concept of sustainability has been proposed and

10 championed as the answer to the impending challenges our society will be facing in the

11 future. It has been a rallying opportunity for the broad earth sciences community and a

12 good starting point for such a community to impact societal and policy decisions;

13 however, it has been an opportunity we have largely missed thus far. We are not the first

14 to notice that the sustainability wave has left geosciences behind. In fact, almost ten years

15 ago, Grimm and Van der Pluijm (2012) lamented the absence of geoscientists at a

16 National Academies Symposium aimed at "Science, Innovation, and Partnerships for

17 Sustainable Solutions."

18 Sustainability theory is rooted in three interconnected domains or pillars: social,

19 economic, and environmental sustainability. Much of the early notion stemmed from the

20 United Nations' initiatives where the basic concepts were sharpened over the last 50

21 years (see Purvis et al., 2018 for a review of concepts through time). The anticipation is

22 that the three pillars, if properly harmonized, will improve both the present and future

23 potential to meet human needs and aspirations (https://sdgs.un.org/goals). So, it is often

24 stated that the main drive behind sustainability — and its corollary initiatives - is to

25 explore the capacity for the biosphere and human civilization to co-exist, in which the

26 term (sustainability) is thrown around as the deus ex machina that will, if correctly

27 implemented, save us and our planet. While it is important for humans to act upon the

28 foreseeable changes to our planet with urgent mitigations---such as the upcoming climate

29 crisis---we fear that the current strategies are too shortsighted and anthropocentric to

30 produce durable solutions. This may be because sustainability education and research are 
31 taking place in the absence of geological sciences, and without deep familiarity with

32 Earth's history and dynamism, these efforts will fall short in protecting our future.

33 The word sustainability is one of the most used words in the current scientific

34 vocabulary (https://xkcd.com/1007/). In fact, by the end of this paper, you will have read

35 the word another 29 times. It has been so overused (or abused) in appropriate and

36 inappropriate ways that it has many critics who find the word vague or nonspecific. We

37 think that the word could be appropriate in the right context but has been haphazardly

38 applied due to a major philosophical gap in most sustainability efforts.

39 We can start with an etymological dig into the original meaning of the word.

40 Sustainability derives from the Latin word sustinēere, formed by sus-, a variant of sub-

41 meaning "under" and tenere, meaning "hold". Therefore, the epistemological meaning of

42 the word is to "hold under." Considering how human-centric we tend to be in our society,

43 one interpretation of the word could be to "hold under" nature to sustain the needs of an

44 overgrowing society. Maybe a more suitable (friendly?) interpretation would be to

45 "hold" - tenere - something to a certain level, to a standard, a potentially ideal datum to

46 which to aspire or regress (in the case of overgrowth).

47 But what is our standard? Our datum? As scientists, we feel the need to define

48 what and how we are measuring and from which baseline. Agreements on the standard to

49 achieve (if we use $\mathrm{CO}_{2}$ levels) often point toward conditions just prior to the Industrial

50 Revolution. However, because humans have been modifying the environment for the last

518000 years (Ruddiman, 2005), why not aim further back in time to the end of the Last

52 Glacial? Or the appearance of Homo erectus? Our society is a mere eye-blink in geologic

53 time; settling on a datum must reckon with this fact.

$54 \quad$ We make the point that every initiative in sustainability and any theoretical

55 application of it should not (and cannot) be enabled without the full consideration of

56 "deep time" that only earth scientists can bring to the table. This shares some similarities

57 with the concept of a "deep time reckoning" introduced by Ialenti (2020) but modified to

58 apply longer temporal perspectives or "timefulness" (Bjornerud, 2018) in using the past

59 as an indispensable framework for the future.

60 Since the world's richest and most privileged people are now throwing their

61 money behind climate engineering (maybe without fully grasping the concept), we think 
62 geologic principles should be implemented swiftly to prevent yet more "unforeseen"

63 consequences. One place to start is at the university level, where sustainability programs

64 are proliferating to the exclusion of earth sciences, with a few timid exceptions.

\section{A Historical Science: the past enlightens the present to guide our future}

We are members of an observation-based historical science; this should be viewed as an advantage and a privilege - nobody can see the world as we can. Unfortunately,

69 those with environmental policy power and market power are not necessarily asking for 70 our advice.

Of the three theoretical pillars of sustainability, the environmental pillar seems to

72 be the one most logically aligned with earth sciences. It makes sense that this pillar

73 should be strongly rooted in the disciplines that study and understand Earth, its past, its

74 climate fluctuations, and its profound transformation through time. Unfortunately, that is

75 not always the case. Depending on the search engine and wording used in one's

76 browsing, the results consistently suggest the lack in depth in geosciences. The top

77 geology programs in the USA are responding differently to the external push in this

78 direction. While some departments have added "environmental" to their names (this has

79 been going on for decades), the involvement of some geoscience departments with

80 neighboring sustainability initiatives go from inaction (hence missing the opportunity) to

81 acknowledgment (upon donors' pressure) but still hesitant impasse, to the complete

82 surrender of their programs to the new trend. Some universities have established

83 pathways for students to receive undergraduate and/or graduate degrees in sustainability

84 (sometimes tagged as environmental sciences or earth systems) in juxtaposition with

85 earth science departments or schools. But perhaps due to the Venn-like relationship

86 between the 'three pillars' and the vagueness of the central concept, these academic

87 programs are a maze of core and elective classes that flit around social sciences, statistics,

88 economics, biology/chemistry, physics, and policy, depending on the chosen specialty

89 track. The most inspired departments might graduate students in sustainability or earth

90 systems with a requirement of one (only 1!) class in earth or natural sciences; and such a

91 class could be a field trip or a farming experience or entirely about ecosystems. We

92 surveyed 40 high-ranking U.S. degree programs in sustainability (or environmental 
93 science) and found that only nine required geology in at least one of their tracks, and of

94 those only three required more than one course (Fig. 1). Geology courses are included on

95 most elective lists, but even so, they are so swamped by other offerings that geology

96 courses make up on average less than $10 \%$ of all electives (Fig. 1). If students are lucky

97 (and maybe well-advised) they might be exposed to something like Global Climate

98 Change Sciences, which some programs are far-sighted enough to include in their course

99 list. However, Earth History, shockingly enough, is not listed as a mandatory class in

100 many programs. It is fairly easy for students to receive a degree in policy or economics or

101 even land use under the large umbrella of sustainability without being exposed to earth

102 sciences.

103 While it is always dangerous to generalize and, of course, there are differences

104 among schools and programs, one cannot escape the extent of the problem. Many

105 institutions proudly tout they are graduating the future leaders in sustainability but they

106 forget to mention that the students do not acquire the tools to really understand earth's

107 processes and past changes. Granted, opportunities to deepen one's knowledge might be

108 available at an individual level such that certain students can expand their geoscience

109 experiences, but the fact that universities are focusing their sustainability training into

110 social sciences, biological sciences, and/or engineering is shortsighted. Climate changes

111 and their impact on our society are understood largely due to the work of geologists;

112 seeing programs that do not keep at least Earth History and Geomorphology among their

113 core mandatory courses is troublesome.

114 It is interesting to notice that European high schools and universities seems to

115 have a more geologic-centric approach to sustainability (and geology overall), and their

116 programs do offer courses such as Dynamic Earth and Planetary Evolution or Earth

117 Surface Evolution (as it responds to climatic changes). As we write this, our two sons are

118 in public middle and high school in Italy where the science curriculum includes earth

119 science (textbook and everything!) in straight balance with chemistry, physics, and

120 biology. This early visibility of geology — whatever the cultural forces behind it — must

121 make it easier for university geoscience programs to be in on the sustainability

122 conversation. 


\section{A confluence of human crises: climate change and infectious diseases}

125 Theoretical links between climatic fluctuations and pandemics have been

126 postulated and discussed for a long time (see Ruddiman, 2005 and its references). When

127 the world stumbled onto SARS-CoV-2 (Severe Acute Respiratory Syndrome

128 CoronaVirus 2) in late 2019, it should not have been such a surprise. This pandemic was

129 a turning point and potentially the opening of Pandora's Box in that it exposes how

130 climatic change expands the intersection between human living spaces and disease

131 carriers, by shifting the global distribution of such carriers (e.g., Beyer et al., 2021).

132 The pandemic offered per se a daunting example with regard to crisis preparation.

133 In the 1970s, the World Health Organization declared victory against diseases (McNeill,

134 1976), as it seemed the diseases that historically afflicted humans were on the retreat after

135 decades of vaccination efforts. Unfortunately, a series of new pandemics (and a fresh new

136 batch of viruses) swept through the world; HIV, SARS, Ebola, MERS, Ebola again and

137 now SARS-2 are showing us how important long-term planning and prevention can be.

138 These "new" viruses are actually "old" (if we carefully reconstruct the zoonosis) and they

139 show we must have a historical perspective even in understanding societal diseases; a

140 society is never immune in its interaction with an ever-changing nature especially when

141 such society is modifying (destroying?) ecosystems at an unprecedented rate (Quammen,

142 2012)

143 McNeill's seminal work in Plagues and People (1976) was an important early

144 contribution to the study of the impact of diseases throughout human history. McNeil

145 poses that history could be read through the lens of pandemics and not necessarily

146 through the powers and military superiority accumulated via armies and gold. His careful

147 review poses the balance between men and diseases sharply in focus (wherein one might

148 momentarily prevail over the other in a dynamic balance) offering an opportunity to

149 explore history in a different way.

150 We surely took the uninvited opportunity given to us by viruses and their

151 predominance on the world news to learn that viruses together with microbes and bacteria

152 have been around for billions of years. Of course we should have known better that such

153 a fundamental force in shaping the planet biota had to be involved with the development

154 of early life on Earth (Krupovic et al., 2019). Without fully embracing a virocentric 
155 perspective on the evolution of life, multiple lines of evidence have been presented

156 showing the central role of viruses in the earth's entire evolution (Koonin and Dolja,

157 2013). There are trillions of viruses in the modern oceans, making them the most

158 numerous biological entities in the world's oceans, profoundly regulating the deep-sea

159 ecosystems, and marine biologists and ecologists are only recently beginning to tackle the

160 effects of viruses on the broader ocean ecology (Zimmer, 2005). Palaeoecologists have

161 been looking into the effects of diseases on paleoenvironments; the example of Poinar

162 and Poinar (2008) on dinosaurs' paleoecology is one that comes to mind. There is plenty

163 of room to start thinking about viruses through deep time and contemplating their impact

164 on the evolution of life on Earth, including our own species. Cesare Emiliani, in a

165 prescient contribution from about 30 years ago, warned us: "Indeed, both Emiliana

166 huxley (Emiliana huxley is a species of coccolithophore) and Homo sapiens appear to be

167 under viral attack... It is of course impossible to predict whether the attacks will be

168 terminal, whether the responsible viruses will mutate themselves out of existence, or

169 whether immunity will develop in one or both species, giving at least temporary

170 reprieve." (Emiliani, 1993).

171 We think an incredible opportunity is in front of our inherently historical science;

172 a science that tracks changes by studying the sedimentary record. If history could be read

173 through the lens of disease (as suggested by McNeil 1976) and extinctions could have a

174 viral (or microbial) component to them (Emiliani, 1993), our skills as geoscientists would

175 be helpful to the conversations about how to prepare for the future. An historical "habit of

176 mind" is advisable for every action we undertake.

178 A grounded embrace of our planet's "dynamic disequilibrium"

179 "The higher we soar, the smaller we appear to those who cannot fly." F. W. Nietzsche

Economists, philosophers, physicists, and engineers got involved early on in the

182 debate about the future of our society and have been active in decision-making processes.

183 They pushed the sustainability 'boat' straight to the highly theoretical level of system

184 (and complex) thinking - hence fundamentally soaring it off the very terra firma to

185 which complex thinking should be anchored: Earth. Sustainability should walk on foot! 
186 With the theorists of the three pillars heavily weighted toward the economic and social 187 sciences, the environmental pillar is left behind to be mostly an engineer's afterthought.

$188 \quad$ Firstly, we need to position earth sciences as the core of the environmental pillar.

189 To do this, we suggest emphasizing the importance of the biosphere as it is linked to the 190 geosphere. This is not a petty fight between sciences but a philosophical need solely

191 pointing to the exposition of a fundamental fact. Biosphere and geosphere have

192 constantly 'danced' together to shape the environment we live in (as elegantly explained

193 by Knoll, 2003). Life's evolution through its long history influenced earth's surface more

194 than one might think and, overall, the central role of plate tectonics - arguably among the

195 most influential revolutions of the last century - has never been fully appreciated by the

196 general public. The role of oxygenic photosynthesis (and the appearance of large

197 quantities of the "poisonous" oxygen in the atmosphere; see Lane, 2002) and the coupled

198 atmosphere and ocean interactions through time illustrate the complex relationship

199 between evolution and environmental changes.

200 In addition to a more balanced treatment of the biosphere and geosphere, we think

201 geomorphology is underrepresented in environmental and sustainability science training.

202 Global landscape evolution through space and time interacts with the atmosphere and

203 hydrosphere, reacting to any dictation of climate and its changes through time. The

204 sedimentary record is the outcome of such interactions. How can a graduate of a

205 sustainability program become suitably aware of landscape change without taking classes

206 in earth history and geology? And then how will this graduate help mitigate the distress

207 of coastal communities related to sea-level rise, or understand the full range of

208 possibilities in terms of flood patterns or erosion rates?

209 The notion that the planet's habitability, as it is nowadays, which fostered the rise

210 of our species, was somehow given to humans as our perfectly designed "living place" is

211 plain wrong. As earth scientists know, the evolution of Earth from its early days has been

212 a winding path, a long great adventure of which we are sorting out the details thanks to

213 the incredible amount of work done by many colleagues over the last few centuries.

214 Fundamental understanding of critical geological phenomena on Earth must be used to

215 solve scientific, engineering, and societal challenges around our future survival.

216 Furthermore, the resilience of global landscapes during a time of rapid perturbations 
217 appears to be the one major control on anything we do to mitigate the changes to come.

218 There is the unsettling feeling that many of the "corrective means" brought up by

219 sustainability studies are more short-term engineering mitigations rather than long-term

220 solutions. Some brute force attempts to control our climate (e.g., carbon removal) bear

221 unpredictable risks via poorly understood feedbacks within the oceans and biosphere.

222 Most of us are aware that the engineering of nature comes with unintended consequences,

223 high costs, and even higher stakes for the society directly impacted (See The Control of

224 Nature, McPhee, 1989).

225

226 The Opportunity:

227 Our planet is in a constant dynamic disequilibrium and within such a state we 228 need to learn how to coexist. This fundamental concept should shape the leadership of the

229 future so that mitigation attempts are not fragile engineering maneuvers pushed upon

230 nature (or editorial stunts by big personalities) but instead are durable solutions that can

231 adapt to forecasted feedbacks and out-of-normal events. Maybe the sustainability camp

232 has been clever at advertising their cause, and maybe geologists have not done such a

233 good job at enticing the public opinion, but we think that attracting well-meaning

234 students into career paths that do not have adequate grounding in earth sciences could be

235 unfortunate for our society (and for the future of such students). For this reason, earth

236 science must be promoted and presented as a core value in the sustainability programs

237 that are now growing across universities.

238 To us, this is an ethical call. We cannot let our society move forward with energy

239 and economic plans without understanding the behavior and limits of the environment we

240 are trying to sustain. Our unique and hard-earned understanding of the past must educate

241 global decisions about climate and energy, and so we have to speak up.

"Faber est suae quisque fortunae." Appio Claudio Cieco 
249 Beyer, R.M., Manica, A., Mora, C. (2021). Shifts in global bat diversity suggest a

250 possible role of climate change in the emergence of SARS-CoV-1 and SARS-CoV-2.

251 Science of The Total Environment, 767: 145413.

252 Bjornerud, M. (2018). Timefulness: How Thinking Like a Geologist Can Help Save the

253 World. Princeton University Press, pp. 1-224.

254 Emiliani, C. (1993) Extinction and viruses. BioSystems, 31: 155-159.

255 Grimm, N., \& Van Der Pluijm, B. (2012). Sustainability needs the geosciences.

256 Eos, 93(44), 441. https://doi.org/10.1029/2012EO440007

257 Ialenti, V. (2020) Deep Time Reckoning: How Future Thinking Can Help Earth Now.

258 The MIT Press, pp. 1-208.

259 Knoll, A.H. (2003). The geological consequences of evolution. Geobiology, 1: 3-14.

260 Koonin, E.V., and Dolja, V.V. (2013). A virocentric perspective on the evolution of life.

261 Curr. Opin. Virol., 3(5):546-557.

262 Krupovic, M., Dolja, V.V., and Koonin, E.V. (2019). Origin of viruses: primordial

263 replicators recruiting capsids from hosts. Nature Reviews Microbiology, Nature

264 Publishing Group, 17 (7), pp.449- 458.

265 Lane, N. (2002). Oxygen: the molecule that made the world. Oxford University Press, pp. $2661-374$.

267 McNeill, W.H. (1975). Peoples and Plagues. Anchor Books, pp. 1-365.

268 McPhee, J., 1989, The Control of Nature. Farrar, Straus and Giroux, New York, pp. 1-

269275.

270 Poinar, G. Jr., and Poinar, R. (2008). What Bugged the Dinosaurs?: Insects, Disease, and

271 Death in the Cretaceous. Princeton University Press, pp. 1-253.

272 Purvis, B., Mao, Y., and Robinson, D. (2018). Three pillars of sustainability: in search of

273 conceptual origins. Sustainability Science. https://doi.org/10.1007/s11625-018-0627-5.

274 Quammen, D. (2012). Spillover: animal infections and the next human pandemic. W.W.

275 Norton \& Company, New York - London, pp. 1-587.

276 Ruddiman, W.F. (2005). Plows, Plagues, and Petroleum: how humans took control of

277 climate. Princeton University Press, Princeton and Oxford, pp. 1-226.

278 Zimmer, C. (2015). A planet of viruses. The University of Chicago Press, pp. 1-122. 
279 Figure 1. The number of required geoscience courses, and the percent geoscience

280 electives, in 40 sustainability or environmental science undergraduate programs in the

281 U.S. These programs typically offer multiple tracks; the data here represent the curricula

282 from the most geoscience-relevant track in each program. Where given a choice, we

283 surveyed the Bachelor of Science degree program. The programs represent a wide

284 geographic range of public, private, and small- and large-population colleges and

285 universities and were listed as top-ranking environmental or sustainability programs at:

286 universities.com, usnews.com, bestvalueschools.com, or environmentalscience.org. The

287 three schools requiring more than one geoscience course include the University of

288 Vermont, University of South Dakota, and Stanford University. 
Geology absence from high-ranked sustainability degrees (U.S.)

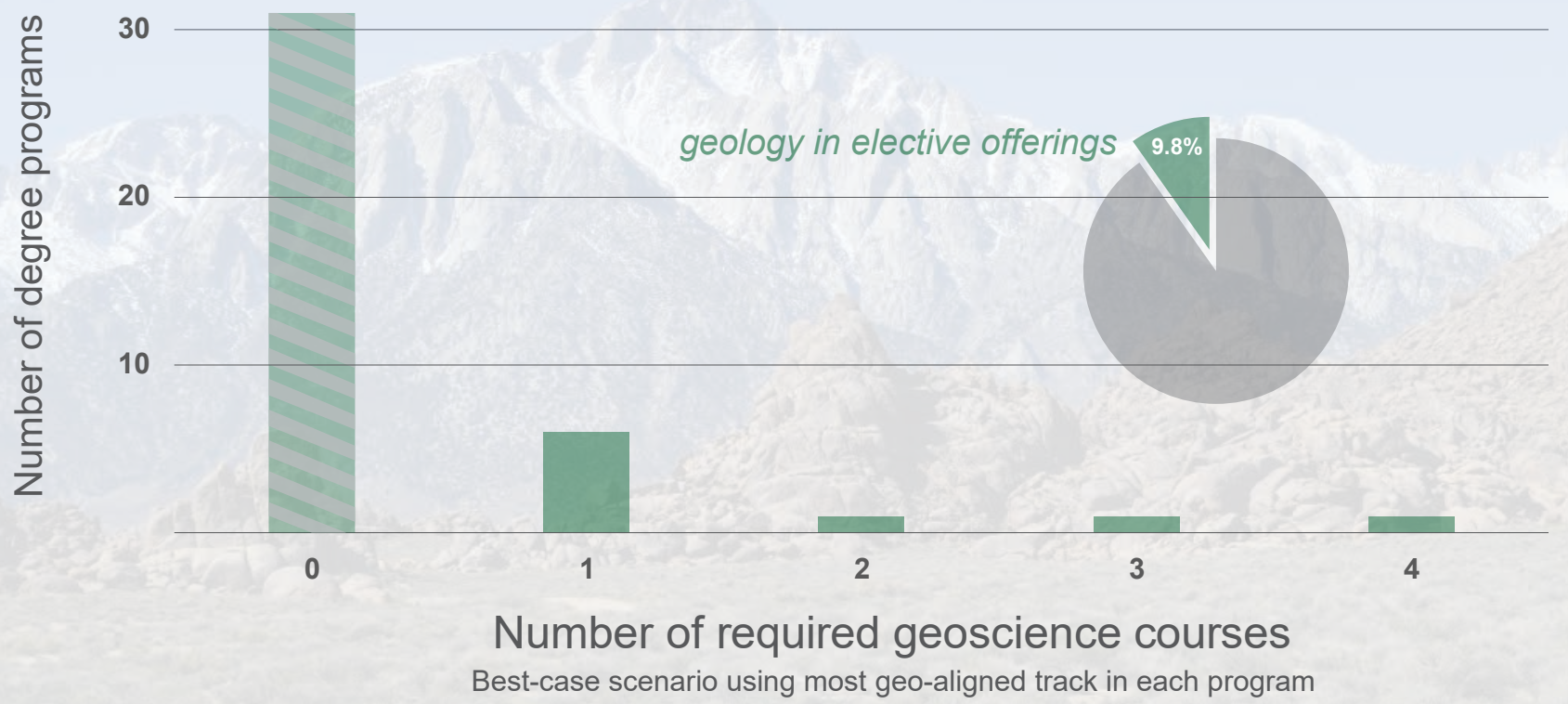

